\title{
PRAKTIK PENGALAMAN LAPANGAN PROGRAM STUDI ADMINISTRASI PENDIDIKAN, SEBUAH REFLEKSI
}

\author{
Oleh: \\ Faridah, Arismunandar dan Syamsurijal Basri \\ Universitas Negeri Makassar \\ (E-mail :faridah@unm.ac.id, arismunandar@unm.ac.id, rijal@unm.ac.id)
}

\begin{abstract}
ABSTRAK
Artikel ini fokus pada pola pelaksanaan Praktik Pengalaman Lapangan (PPL) pada program Studi Administrasi Pendidikan (AP) Fakultas Ilmu Pendidikan Universitas Negeri Makassar. penelitian deskriptif dengan pendekatan kualitatif. Sumber data dalam penelitian ini adalah dosen pendamping, kaprodi AP, mentor, dan mahasiswa AP yang telah memprogramkan mata kuliah PPL. Informan utama dari penelitian ini adalah mahasiswa Administrasi Pendidikan yang telah mengikuti program PPL. Teknik pengumpulan data dilakukan melalui wawancara, studi dokumentasi dan focus group discussion. Hasil penelitian memperlihatkan bahwa pelaksanaan PPL pada prodi AP belum memiliki pola yang baku. Salah satu faktor yang menyebabkan hal ini karena AP merupakan prodi yang tidak menghasilkan guru, sementara panduan untuk PPL non-keguruan belum tersedia. Program dan aktivitas yang dilakukan oleh mahasiswa selama berada di lokasi PPL belum terstruktur dan terkesan tidak jelas. Pembimbingan yang dilakukan oleh dosen pembimbing dan pamong juga belum fokus, terutama untuk mahasiswa yang mengikuti program KKN PPL terpadu.
\end{abstract}

Kata kunci: Praktik Pengalaman Lapangan, Program non-keguruan

\begin{abstract}
This article focuses on the pattern of implementing Field Experience Practices (PPL) in the Educational Administration Study Program (AP) of the Faculty of Education, Makassar State University. descriptive research with a qualitative approach. The data sources in this study were accompanying lecturers, heads of APs, mentors, and AP students who had programmed the PPL course. The main informants of this study were Educational Administration students who had taken the PPL program. Data collection techniques were conducted through interviews, documentation studies and focus group discussions. The results of the study show that the implementation of PPL in AP study programs does not have a standard pattern. One factor that causes this is because the AP is a study program that does not produce teachers, while the guidelines for non-teacher PPL are not yet available. Programs and activities carried out by students while at the PPL location are not structured and seem unclear. Guidance conducted by supervisors and tutors is also not focused, especially for students who take part in the integrated KKN PPL program.
\end{abstract}

Key words: Field Experience Practice, non-teaching program

\section{PENDAHULUAN}

Praktik Pengalaman Lapangan (PPL) merupakan kegiatan pembelajaran yang diperoleh oleh mahasiswa yang mencakup latihan mengajar serta tugas-tugas kependidikan di luar mengajar secara terbimbing dan terpadu untuk memenuhi persyaratan pembentukan profesi kependidikan.

PPL adalah serangkaian kegiatan yang diprogramkan bagi mahasiswa LPTK, yang meliputi baik latihan mengajar maupun latihan di luar mengajar. Kegiatan ini merupakan ajang untuk membentuk dan membina kompetensi-kompetensi profesional yang disyaratkan oleh pekerjaan guru atau lembaga kependidikan lainnya. Sasaran yang ingin dicapai adalah kepribadian calon pendidik yang memiliki seperangkat pengetahuan, keterampilan, nilai dan sikap, serta pola tingkah laku yang diperlukan bagi profesinya serta cakap dan tepat menggunakannya di dalam menyelenggarakan pendidikan dan pengajaran, baik di sekolah maupun di luar sekolah (Oemar Hamalik, 2009).

Pengalaman lapangan beroreintasi pada kompetisi, pembentukan kemampuan-kemampuan profesional siswa calon guru atau tenaga kependidikan lainnya dan dilaksanakan, dikelola dan ditata secara terbimbing dan terpadu (Oemar Hamalik 2009. 
Dari uraian di atas dapat disimpulkan bahwa Praktik Pengalaman Lapangan (PPL) adalah serangkaian kegiatan yang diprogramkan bagi mahasiswa LPTK, yang meliputi baik latihan mengajar di dalam kelas (yang bersifat akademik) maupun latihan mengajar di luar kelas (yang bersifat non akademik). Kegiatan ini merupakan ajang untuk membentuk dan membina kompetensikompetensi profesional yang diisyaratkan oleh pekerja guru atau tenaga kependidikan yang lain. Persepsi mahasiwa terhadap PPL adalah dengan PPL dapat memberikan pengalaman bagi mereka baik dalam bidang pembelajaran dan manajerial di sekolah maupun lembaga dalam rangka melatih dan mengembangkan kompetensi menjadi guru salah satunya dibentuk melalui program PPL.

Selama melaksanakan PPL, mahasiswa mendapat bimbingan dari Guru Pamong. Dasmo \& Sumaryati (2014: 58) menjelaskan bahwa Guru Pamong merupakan guru bidang studi tertentu yang memiliki tugas mendampingi dan membimbing mahasiswa praktikan selama melakukan kegiatan PPL di sekolah. Ni'mah (2014: 338) juga mengemukakan bahwa Guru Pamong sebagai master teacher yang membimbing mahasiswa dalam melaksanakan tugas-tugas guru.

Namun demikian, seiring dengan perjalanan PPL di lapangan terdapat beberapa kendala yang secara tidak langsung akan menyebabkan kegiatan PPL menjadi kurang maksimal di lapangan. Mintardja dalam Achmad (2014) memaparkan bahwa salah satu permasalahan dalam PPL terlihat dalam hal Guru Pamong yang masih belum sepenuhnya melaksanakan tugas dan peran secara aktif atau dengan kata lain bahwa kinerjanya belum maksimal. Hal ini kasuistik tidak terjadi pada setiap sekolah, karena banyak faktor pendukungnya meski pada hal-hal tertentu Guru
Pamong telah melaksanakan tugas dengan baik meski baru pada tataran proses pembelajaran saja. Hal ini tentu akan memberikan pengaruh pada hasil pengalaman dan prestasi yang diperoleh oleh mahasiswa serta kesiapan mahasiswa untuk terjun ke lapangan nantinya setelah selesai menempuh pendidikan.

Sebuah penelitian yang dilakukan oleh Bayu dkk (2010) menjelaskan bahwa prestasi PPL memberikan pengaruh secara signifikan terhadap kesiapan mahasiswa menjadi guru ekonomi/akuntansi yang professional. Oleh karena itu, dari hasil penelitian ini dapat dimaknai bahwa prestasi PPL akan mempengaruhi terhadap kesiapan untuk menjadi seorang tenaga pendidik maupun tenaga kependidikan yang profesional.

Universitas Negeri Makassar sebagai Lembaga Pendidikan dan Tenaga Kependidikan (LPTK) tidak hanya fokus pada bagaimana menghasilkan guru yang profesional, melainkan juga tenaga kependidikan. Undang-Undang Sistem Pendidikan Nasional Nomor 20 tahun 2003 pasal (1) menyatakan bahwa tenaga kependidikan adalah anggota masyarakat yang mengabdikan diri dan diangkat untuk menunjang penyelenggaraan pendidikan. Lebih lanjut pasal 39 menyatakan bahwa tenaga kependidikan ini bertugas melaksanakan "administrasi, pengelolaan, pengembangan, pengawasan, dan pelayanan teknis untuk menunjang proses pendidikan pada satuan pendidikan (UU Sisdiknas, 2003). Dalam Peraturan Menteri Ristek, Teknologi, dan Pendidikan Tinggi (Permenristekdikti) Nomor 44 tahun 2015 tentang Standar Nasional Pendidikan Tinggi (SNPT), tenaga kependidikan diangkat untuk menunjang penyelenggaraan pendidikan tinggi antara lain pustakawan, tenaga administrasi, laboran, teknisi, serta pranata teknik informasi (Permenristekdikti, 2015). Dengan demikian, salah 
satu tantangan LPTK di bidang pendidikan adalah menyiapkan dan menghasilkan tenaga kependidikan yang memiliki kemampuan di bidang administrasi, pengelolaan, pengembangan, pengawasan, dan pelayanan teknis di unit satuan pendidikan dsar dan menengah, dan pendidikan tinggi.

Program Studi Administrasi Pendidikan adalah penyelenggara kegiatan pendidikan yang luarannya tidak hanya diperuntukkan menjadi guru. Berdasarkan Rencana Strategik Prodi AP FIP UNM tahun 2015 - 2019, visi prodi AP adalah "Menjadi pusat pelayanan pengkajian dan pengembangan ilmu administrasi pendidikan untuk menghasilkan insan yang cerdas, profesional, dan bermartabat" (Renstra AP, 2015). Renstra Prodi AP juga menyatakan bahwa Prodi ini bertujuan menghasilkan lulusan yang menguasai konsep teoretis dan mampu mengaplikasikan keahliannya di bidang bidang manajemen dan kepemimpinan pendidikan, perencanaan pendidikan, Pendidikan dan Pelatihan, kepengawasan dan supervisi pendidikan, dan pengambilan keputusan dan kebijakan pendidikan (Renstra AP, 2015).

Praktik Pengalaman Lapangan merupakan mata kuliah yang sengaja dirancang untuk menyiapkan mahasiswa agar memiliki kemampuan yang terpadu dan utuh sesuai dengan bidangnya. Di prodi AP, mata kuliah PPL ditawarkan di semester VII dan VIII. Ada yang dalam bentuk PPL Reguler, ada juga dalam bentuk KKN/PPL terpadu. Berdasarkan Buku Panduan Pengalaman Lapangan UNM tahun 2016, PPL bertujuan untuk mengembangkan kemandirian, meningkatkan kemampuan untuk menilai diri, memberikan wawasan tentang kehidupan guru di sekolah, termasuk budaya dan organisasi sekolah, dan mendorong perkembangan nilai profesional sebagai pendidik (UPT PPL UNM, 2016, hal.2).
Secara umum, panduan PPL yang disediakan oleh UPT PPL UNM dikhususkan untuk mahasiswa calon guru. Sedangkan mahasiswa non-keguruan, atau mahasiswa yang bidangnya adalah untuk menjadi tenaga kependidikan, panduan PPLnya diserahkan kepada prodi masing-masing. Khusus untuk prodi AP, pelaksanaan PPLnya dilaksanakan di sekolah, di UPTD, maupun LPMP, namun panduan pelaksanaan kegiatan mahasiswa selama PPL belum terdokumentasikan dengan baik.

PPL bagi calon guru misalnya, merupakan rangkaian kegiatan yang dilakukan oleh mahasiswa calon guru agar mereka memiliki pengetahuan dan pemahaman tentang bagaimana menjadi guru "being a teacher" agar kelak mereka memiliki kompetensi yang utuh sebagai seorang calon guru. Dengan demikian, maka untuk prodi AP, PPL merupakan merupakan rangkaian aktivitas yang dilakukan oleh mahasiswa AP, sesuai dengan tupoksi sebagai tenaga kependidikan, agar mereka memiliki pengetahuan dan pemahaman tentang tugas dan tanggung jawab sebagai tenaga kependidikan.

Fenomena yang terjadi di lapangan, konsep PPL prodi AP ini belum menemukan pola yang jelas. Aktivitas apa saja yang dilakukan oleh mahasiswa PPL, berapa lama mereka berada di lokasi PPL, bagaimana mekanisme pembelajaran yang mereka alami, masih belum sepenuhnya terlihat dalam pelaksanaan PPL di lapangan. Program dan aktivitas apa yag perlu dilakukan oleh mahasiswa AP ketika mereka memprogramkan MK PPL masih belum jelas. Akibatnya, mahasiswa merasa bahwa mereka sekedar turun ke lokasi PPL, dan rangkaian kegiatan pembelajaran yang mereka lakukan bervariasi tergantung pada lokasi PPL, kreativitas pembimbing, dan kreativitas mahasiswa itu sendiri. Penelitian ini mencoba untuk 
melakukan studi awal untuk mengidentifikasi kebutuhan dalam rangka mendesain pola dan panduan pelaksanaan PPL prodi Administrasi Pendidikan, Fakultas Ilmu Pendidikan, Universitas Negeri Makassar.

DeAngleis dan O'Connor memaparkan bahwa berdasarkan penelitan yang mereka lakukan, terdapat lebih banyak orangorang yang memiliki sertifikat sebagai administrator pendidikan dibanding posisi yang tersedia untuk pekerjaan tersebut. Salah satu rekomendasi yang mereka tuliskan adalah diperlukannya pelatihan yang lebih spesifik dan dukungan untuk proses transisi agar administrator pendidikan ini dapat terserap di dunia kerja.

Setiap 4 tahun, prodi AP melakukan review kurikulum untuk melihat keterkaitan antara kurikulum dengan kebutuhan dunia kerja. Selain mempertimbangkan kebutuhan stakeholder terkait, prodi AP FIP UNM juga mengacu kepada KKNI dan kurikulum AP yang digunakan di universitas lain seperti Universitas Negeri Malang dan Universitas Pendidikan Indonesia. Sayangnya, review kurikulum ini lebih banyak mengacu pada mata kuliah dan sebaran mata kuliah yang ada. Pembahasan mengenai konsep PPL dan rangkaian kegiatan di dalamnya belum dibahas secara terperinci.

Salah satu tantangan dalam menghasilkan luaran yang memiliki pengetahuan dan kompetensi dalam bidang perencanaan, pengawasan, supervisi dan evaluasi, dan kebijakan pendidikan adalah bagaimana memperkaya mahasiswa dengan keterampilan-keterampilan yang sifatnya teknis dan praktis. Keterampian ini dapat diperkaya melalui Mata Kuliah PPL. Bisa dikatakan, PPL merupakan salah satu tempat yang paling strategis untuk melakukan hal ini. Mata Kuliah PPL ini merupakan bagian dari kurikulum pendidikan yang meyediakan ruang bagi mahasiswa AP untuk mengenali secara lebih dalam tentang profesi tenaga kependidikan. Beberapa contoh tenaga kependidian adalah sebagai pustakawan, tenaga administrasi, laobran, dan teknisi. Hal ini tentu menjadi tantangan bagi prodi AP untuk mensinergikan antara kurikulum yang tersedia, proses perkuliahan yang dialami oleh mahasiswa, dan kompetensi yang dibutuhkan oleh lapangan kerja di bidang pengelolaan pendidikan.

Secara umum, tujuan PPL prodi AP adalah agar mahasiswa memiliki pengalaman nyata dan kontekstual terkait pengetahuan, sikap, dan keterampilan yang dapat menunjang penguasaan kompetensi sebagai tenaga kependidikan di unit satuan pendidikan, baik pendidikan dasar dan menengah, maupun pendidikan tinggi, maupun di sektor lain yang terkait dengan pendidikan dan pelatihan. Program dan rangkaian kegiatan selama mahasiswa berada di lokasi PPL menjadi penting untuk didesain secara terstruktur, agar dapat memfasilitasi mahasiswa belajar dari pengalaman nyata dan kontekstual tersebut.

Hasil refleksi dari dosen pendamping, pengelola PPL, dan mahasiswa PPL memperlihatkan bahwa aktivitas mahasiswa PPL dari prodi AP tidak jelas, karena berjalan sendirisendiri sesuai dengan persepsi mahasiwa. Beberapa mahasiswa bahkan tidak mengetahui dengan jelas apa yang harus mereka lakukan ketika memprogramkan MK PPL ini. Kehadiran Dosen Pendamping juga umumnya hanya pada saat mengantar dan menjemput mahasiswa. Progam dan rangkaian kegiatan PPL berdasarkan profil lulusan yang ingin dicapai masih belum tercermin dalam pelaksanaan PPL mahasiswa.

Hasil refleksi awal dari peserta PPL ditemukan bahwa mereka terkadang mengalami kebingungan tentang aktivitas yang harus 
dilakukan di lokasi PPL. PPL lebih kepada kegiatan berkunjung ke sekolah dan membantu sekolah untuk hal-hal terkait administrasi sekolah, sangat teknis. Namun sejauh mana praktik pengalaman itu membantu mereka untuk menjadi seorang calon tenaga kependidikan yang professional belum sepenuhnya terukur karena tidak adanya mekanisme pemberikan umpan balik yang jelas. Peserta PPL juga merasa bahwa mereka belum memiliki program yang jelas selama berada di lokasi PPL. Rangkaian aktivitas kegiatan biasanya tergantung dari kreativitas mereka, dosen pendamping dan lokasi pelaksanaan PPL.

Berdasarkan uraian diatas, maka focus dalam penelitian ini adalah pada persepsi dan ekspektasi mahasiswa tentang PPL, dan refleksi pengalaman mereka ketika memprogamkan mata kuliah PPL di lokasi terkait.

\section{METODE PENELITIAN}

Jenis penelitian ini adalah penelitian deskriptif dengan pendekatan kualitatif. Karena penelitian ini merupakan studi awal, penelitian ini fokus pada pola pelaksanaan PPL yang selama ini telah dilakukan. Pola pelaksanaan PPL yang dieksplorasi adalah pelaksanaan PPL untuk program sarjana kependidikan progam studi Administrasi Pendidikan. Sumber data dalam penelitian ini adalah dosen pendamping, kaprodi AP, mentor, dan mahasiswa AP yang telah memprogramkan mata kuliah PPL.

Teknik pengumpulan data dilakukan dengan melakukan wawancara, $F G D$, dan studi dokumentasi. Wawancara mendalam dilakukan kepada dosen pendamping, kaprodi AP, dan stakeholder terkait yang berasal dari lokasi pelaksanaan PPL. Wawancara dilakukan untuk menggali tentang pengalaman dan praktek-praktek baik yang telah dilakukan dalam pelaksanaan PPL untuk membantu mahasiswa AP agar memiliki bekal pengetahuan dan pengalaman yang cukup untuk menjadi seorang calon tenaga kependidikan yang professional. Perakyla (2008) menyatakan bahwa wawancara dapat membantu untuk menemukan isu-isu terkait topik yang diteliti. Wawancara juga dilakukan untuk memperoleh masukan tentang hal-hal yang perlu diperbaiki dan ditingkatkan dalam pelaksanaan PPL Prodi AP.
Wawancara diawali dengan menggali persepsi dan pemahaman dosen pendamping, kaprodi, dan stakeholder terkait tentang esensi PPL bagi mahasiswa program S1 Prodi Administrasi Pendidikan. Aspek ini menjadi salah satu hal yang krusial untuk digali karena terkait dengan Kerangka Kualifikasi Nasional Indonesia (KKNI).

Dokumen yang dijadikan sumber data pada penelitian ini adalah panduan pelaksanaan PPL Universitas Negeri Makassar, instrumeninstrumen penilaian selama PPL, produk PPL, dan jadwal kegiatan selama mengikuti PPL, laporan hasil PPL. Menurut Fitzgerald (2007), dokumendokumen ini dapat digunakan untuk memahami konteks dan budaya dari institusi pendidikan, dan ini dapat dikaitkan dengan persepsi tentang esensi PPL itu sendiri.

FGD dilakukan kepada mahasiwa prodi AP yang telah mengikuti PPL, baik PPL reguler, maupun PPL yang terintegrasi dengan Kuliah Kerja Nyata (KKN), yang dikenal dengan istilah KKN/PPL terpadu. Focus Group Discussion dilakukan untuk memperoleh informasi yang lebih mendalam mengenai pelaksanaan PPL. Menurut Barbour dan Schostak (2005), FGD memungkinkan untuk memperoleh informasi yang kadang-kadang tidak bisa diperoleh melalui wawancara individu. Pelaksanaan FGD dipandu 
langsung oleh peneliti. Peneliti menyadari sepenuhnya posisi sebagai dosen sekaligus peneliti yang dapat berdampak adanya kesan superioritas terhadap para informan, seperti yang dikemukakan oleh Barbour dan Schostak (2005). Oleh karena itu, tim peneliti memulai FGD dengan menyampaikan bahwa tujuan FGD adalah untuk mencari tahu pengalaman mereka dalam pelaksanaan PPL. Ketika bertanya dan memandu diskusi, peneliti memperlihatkan penghargaan terhadap sudut pandang peserta FGD.

\section{HASIL PENELITIAN}

\section{Persepsi dan Ekspektasi tentang PPL}

Untuk menggali tentang aktivitas mahasiswa selama PPL, diskusi diawali dengan menanyakan apa yang mereka pahami tentang PPL dan ekspektasi mereka. Salah satu mahasiswa menyatakan bahwa menurut dia, PPL adalah tentang belajar hal-hal yang sifatnya teknis. Seperti yang dinyatakan sebagai berikut:

Jadi, berdasarkan kurikulum yang
ada dijurusan, PPL dalam bayangan
saya adalah belajar tentang hal-hal
teknis yang terkait dengan
kesupervisian, diklat, kepengawasan
sampai pada kegiatan teknis lain
seperti mengarsip dan menginput
data

Mahasiswa lain menyatakan bahwa PPL adalah tentang belajar sesuatu yang baru yang fokusnya disesuaikan dengan unit atau tempat pelaksanaan PPL. Ada juga yang berharap bahwa melalui PPL, mereka akan belajar dan fokus pada satu aspek, karena sebagai peserta PPL mereka akan ditempatkan di unit-unit tertentu dalam satu wilayah kerja.

saya sendiri sebenarnya mau sekali kalau apa yang di pelajari selama kuliah misalnya Manajemen DIKLAT juga di praktekkan di sana, untuk mengetahui apakah sudah sesuai yang kita pelajari, sesuai perkembangan yang terjadi, atau ada yang lebih maju di sana. Dalam DIKLAT itu, itu ekspektasi awal yang saya pahami untuk ketika akan PPL.

Pemahaman saya terkait PPL, apa yang sudah kita pelajari terkait teori-teori bisa diaplikasikan pada saat PPL, kita bisa mengembangkan lagi apa yang menjadi kajian keimuan kita di bidang Admnistrasi Pendidikan. Program dan Aktivitas selama PPL

Terlihat bahwa secara umum, persepsi dan ekspektasi mahasiswa mengenai PPL adalah peluang untuk mengaplikasikan dan mempraktikkan apa yang telah mereka pelajari di kampus.

Penelitian ini juga menanyakan tentang perencanaan program dan aktivitas yang akan mereka lakukan selama mengikuti PPL. Ketika ditanyakan kepada mahasiswa apakah mereka memiliki perencanaan program dan kegiatan yang akan dilakukan selama mengikuti PPL, semuanya menjawab bahwa mereka tidak memiliki perencanaan program yang jelas untuk PPL. Umumnya, ketika mereka datang ke lokasi PPL, sekolah akan memberikan tugas kepada mereka yang terkait dengan ketatausahaan, kearsipan, dan sejenisnya.

\section{Tahapan dalam Pelaksanaan PPL}

Salah satu pertanyaan dalam wawancara adalah mengenai tahapan kegiatan yang mahasiswa lakukan selama PPL. Beberapa mahasiswa memulai kegiatan PPL nya dengan melakukan observasi. Namun observasi yang dilakukan hanya sebatas pengamatan biasa dan tidak menggunakan lembar observasi. Seperti yang dijelaskan oleh mahasiswa sebagai berikut:

Selama 1-2 minggu itu masih tahap observasi. Apa-apa yang dibutuhkan disana, apa kendalanya, karena pertama 
datang disana, mereka mencari mahasiswa jurusan Pendidikan Luar Sekolah (PLS), karena disana kan lembaga non formal, yang diperlukan adalah mahsiswa PLS. Jadi yang kita lakukan adalah observasi 1-2 minggu karena kami juga tidak tahu apa yang bisa dikerjakan di sana. Yang kami rasakan, tidak banyak yang bisa kami lakukan karena jadwal kedatangan kami ternyata tidak sesuai dengan jadwal kegiatan di kantor.

Mahasiswa lain yang melakukan PPL di kantor prodi AP di Kampus Tidung FIP UNM menjelaskan bahwa ketika dia PPL, sama sekali tidak ada observasi, langsung disuruh bekerja saja.

Selama FGD kami juga menanyakan apakah ada inisiatif dari unit penerima mahasiswa PPL untuk menawarkan program yang bisa dikerjakan oleh mahasiswa. Berikut penjelasan mahasiswa:

Kalau kemarin kami diminta oleh pamong untuk membuat program yang berhubungan dengan PAUD, khusus untuk orang tua siswa, karena selama ini para orang tua tidak ada kegiatan. Jadi waktu itu kami berinisiatif untuk membuat kegiatan yang melatih mereka kerajinan. Inisiatif itu muncul karena pamong melihat kami hanya fokus pada kegiatan sebagai operator komputer saja. Jadi kami disarankan untuk membuat progam yang melibatkan orang tua siswa.

Pengalaman lain diceritakan oleh mahasiswa yang melakukan PPL di Kantor Dinas Pendidikan:

Kalau di dinas pendidikan, bisa dikatakan sama sekali tidak ada kegiatan karena waktu itu bulan Februari, program kerja di bidang sarana dan prasarana sudah tidak ada. Kata orang dinas, semua program sudah selesai, tinggal laporan pertanggungjawaban saja. Kata mereka, kami datangnya terlambat, kenapa baru masuk setelah pekerjaan sudah tidak ada

Lebih lanjut mereka menjelaskan bahwa mereka hadir setiap hari di lokasi PPL, tetapi sering tidak ada aktivitas atau pekerjaan yang harus dilakukan.

Hasil wawancara tersebut memperlihatkan bahwa tahapan kegiatan yang dilakukan mahasiwa bervariasi tergantung konteks dimana mereka melakukan PPL. Selain itu, mahasiswa melihat tidak adanya kegiatan yang jelas selama PPL karena sebelumnya tidak ada komunikasi dan koordinasi antara prodi, pengelola PPL, dan unit/kantor tempat pelaksanaan PPL.

\section{PPL Reguler dan KKN PPL Terpadu}

Di UNM, terdapat beberapa skema pelaksanaan PPL, diantaranya PPL Reguler dan KKN PPL Terpadu. PPL reguler adalah PPL yang dilakukan oleh mahasiswa selama 2 bulan yang pelaksanaannya fokus pada PPL saja. Sedangkan KKN-PPL Terpadu adalah progam dimana mahasiswa melakukan KKN dan PPL pada waktu yang bersamaan. Penelitian ini juga menanyakan persepsi mahasiswa tentang kedua skema ini.

Umumnya mahasiswa berpendapat bahwa PPL reguler merupakan pilihan yang lebih baik dibandingkan KKN PPL Terpadu. Menurut mereka, KKN PPL Terpadu membuat mereka tidak maksimal baik dalam pelaksanaan PPL maupun KKN. Berikut beberapa kutipan hasil FGD:

Menurut saya lebih baik PPL reguler biasa. Karena kalau KKN-PPL ada dua kegiatan, $80 \%$ PPL, $20 \%$ KKN. Sementara ketika kami melakukan PPL di kantor, kami tidak bisa meninggalkan kantor sampai selesai jam kantor. Kami pernah di kantor lurah sampai jam satu malam membantu, karena tidak bisa kami lakukan pada jam kerja. Makanya kurang fokus.

Menurut saya, lebih baik PPL Reguler karena bisa lebih fokus dibandingkan KKN PPL reguler. Meskipun katanya KKN PPL terpadu bisa mempercepat proses penyelesaian studi. KKN atau PPL reguler sebenarnya bisa membuat 
kami lebih fokus. Misalnya untuk KKN selama 2 bulan, pada mingguminggu pertama bisa kami gunakan untuk observasi dan berkenalan dengan warga setempat. Jadi masih ada waktu sekitar 6 minggu untuk menyusun program dan mencari sumber dana untuk kegiatan. Hal yang sama juga bisa dilakukan untuk PPL.

\section{Menurut saya pribadi sebaiknya memang dipisahkan antara KKN dan PPL. Karena memang beda fokus. Waktu juga sulit sekali kami atur, antara program yang ada di kantor dengan program yang ada di masyarakat.}

Hasil diskusi memperlihatkan bahwa selain berpendapat bahwa KKN dan PPL sebaiknya dipisahkan karena fokusnya yang berbeda, mahasiswa juga menemukan kesulitan dalam mengatur waktu antara kegiatan KKN dan PPL. Mahasiswa juga merasakan kebingungan mengenai tupoksi KKN PPL terpadu yang berdampak terhadap program dan kegiata yang harus mereka kerjakan selama berada di lapangan.

\section{Peran Pamong dan Dosen Pendamping}

Salah satu aspek penting dalam pelaksanaan PPL adalah peran pamong dan dosen pendamping. Hasil penelitian menunjukkan minimnya komunikasi dan interaksi antara pamong dan dosen pendamping. Hal ini berdampak terhadap pengawasan dan kegiatan yang dilakukan oleh mahasiswa selama PPL. Isu mengenai komunikasi antara universitas dan lokasi pelaksanaan PPL kembali dikemukakan oleh mahasiswa. Salah seorang mahasiswa menyatakan:
Seharunya memang ada perbincangan awal antara pendamping. Hal ini penting dilakukan agar mahasiswa dan pamong mengetahui peran masing- masing. Termasuk bagaimana pola pengawasan, apa yang harus dikerjakan oleh mahasiswa, dan apa yang harus dilakukan jika mahasiswa

\section{tidak melaksanakan tugas sesuai dengan aturan.}

Mahasiswa lain bercerita bahwa mereka kadang memperoleh bimbingan dan masukan dari pamong dalam pelaksanaan PPL ketika melakukan diskusi bersama. Seperti yang disampaikan sebagai berikut:

pada saat penyusunan program kami sharing dengan pamong, kegiatan apa saja yang dapat atau bisa kami laksanakan di UPTD. Kemudian beliau memberikan saran misalnya lomba cerdas cermat dan sebagainya yang mengarah ke bidang pendidikan. Kemudian, masalah anggaran juga beliau bimbing kami dimana bisa dapat dana untuk melaksanakan program tersebut.

Ketika ditanyakan mengenai frekuensi pertemuan dan pembimbingan dengan dosen pembimbing, mahasiswa menceritakan bahwa petemuan biasanya hanya terjadi di awal dan akhir pelaksanaan PPL saja. Berikut beberapa kutipan hasil diskusi:

\begin{abstract}
Seingat saya sampai 3 kali bertemu dengan dosen pembimbing. Awal masuk PPL, kedua di pertengahan, ketika PPL lewat 2 bulan, saya komukasi, dan dosen pendamping cuma mengatakan untuk mengikuti prosedur dan aturan yang ada di lokasi PPL. Yang terakhir, itu yang ketiga, ketika saya minta untuk penarikan. Tapi selama pelaksanaan $P P L$, dosen pembimbing tidak pernah datang ke lokasi PPL.
\end{abstract}

Ada juga yang bahkan tidak pernah bertemu langsung dengan dosen pembimbingnya.

Seperti yang dijelaskan sebagai berikut:

Kalau saya, tidak pernah bertemu
langsung dengan dosen pendamping.
Komunikasi kami lakukan hanya
melalui telepon. Minggu pertama
kami di lokasi, komunikasi secara
intens kami lakukan. Tapi setelah itu
sudah tidak ada lagi komunikasi
sampai dengan penarikan (Peserta
KKN PPL terpadu)

Kalau saya, tidak pernah bertemu langsung dengan dosen pendamping. Komunikasi kami lakukan hanya melalui telepon. Minggu pertama kami di lokasi, komunikasi secara intens kami lakukan. Tapi setelah itu sudah tidak ada lagi komunikasi KKN PPL terpadu) 
Hasil FGD di atas memperlihatkan bahwa mahasiswa tidak memperoleh pembimbingan dan pembinaan yang cukup selama melakukan PPL, baik oleh pamong maupun oleh dosen pembimbing. Menurut mahasiswa, minimnya komunikasi dan interaksi antara mahasiswa, pamong, dan dosen pendamping memberikan pengaruh terhadap kualitas PPL yang mereka lakukan.

\section{Masukan Mahasiswa untuk PPL ke Depan}

Di bagian akhir wawancara dan FGD kami menanyakan kepada mahasiswa apa harapan dan usulan mereka agar PPL prodi Administrasi Pendidikan bisa lebih baik lagi ke depan. Beberapa usuluan disampaikan oleh mahasiwa. Mulai dari jadwal pelaksanaan PPL, panduan PPL, kejelasan kegiatan selama PPL, peran mentor/pamong dan dosen pembimbing, dan reviu kurikulum AP sebagai dasar pengembangan program dan kegiatan PPL. Berikut beberapa kutipan hasil diskusi:

Harapan saya, jangan sampai ada kesan PPL itu secara otomatis menggugurkan mata kuliah. Kemudian, perlu diperjelas apa sebenarnya yang harus kami kerjakan selama mengikuti PPL. Mungkin perlu diadakan pertemuan awal antara prodi, pihak LPM, dengan unit/dinas dimana mahasiswa ditempatkan. Intinya supaya ada kegiatan yang jelas. Tidak seperti sekarang, PPL seperti mengisi waktu kosong saja.

Mahasiswa lain menyampaikan:

Kalau saya, paling tidak, ada pedoman pelaksanaan PPL.
Idealnya ada yang dibuat oleh jurusan sebagai pedoman pelaksanaan PPL. Minimal ada tujuan dan sasaran yang jelas, jenis program dan muatannya.

Mahasiswa juga memberikan saran mengenai peran dosen pembimbing. Dijelaskan:

Harapan saya, kalau bisa, dosen pembimbing bisa turun langsung $k e$ lapangan untuk membimbing mahasiswa, melihat bagaimana mahasiswanya di lapangan supaya bisa berkomunikasi langsung, dan bisa memberikan masukan kepada mahasiswa

Beberapa mahasiwa menyarankan agar prodi AP kembali melakukan kajian kurikulum untuk mempertegas kompetensi dan kajian keilmuan Administrasi Pendidikan.

Kalau saya lebih kompleks sebenarnya. Jurusan perlu untuk melihat kembali kemana sebenarnya orientasi jurusan Administrasi Pendidikan. Apakah mencetak tenaga keguruan, atau tenaga kependidikan. Orientasi inilah yang menjadi acuan untuk pelaksanaan PPL. Selain itu, sebelum pelaksanaan PPL, mahasiswa sebaikna diberikan pengarahan atau pembimbingan. Diperlukan keseriusan dari pihak pimpinan jurusan, pamong, agar mahasiswa bisa memperoleh bimbingan yang maksimal.

Mahasiswa juga memberikan masukan supaya kurikulum didesain sedemikan rupa agar memungkinkan mahasiswa bisa selesai tepat waktu, 4 tahun. Menurut mereka, salah datu faktor yang menyebabkan mereka terlambat selesai adalah karena harus memprogramkan PPL dan KKN ketika sudah habis mata kuliah.

\section{PEMBAHASAN}




\section{Kurikulum AP dan Esensi PPL}

Hasil penelitian menunjukkan bahwa secara umum belum terdapat pola baku mengenai pelaksaaan PPL bagi mahasiswa Administrasi Pendidikan. Tujuan dan sasaran PPL bagi mahasiswa AP belum secara jelas ditemukan dalam pelaksanaan PPL yang sudah berjalan selama ini. Akibatnya, ketika mahasiswa turun ke lapangan untuk melaksanakan PPL, aktivitas yang mereka lakukan cenderung tidak terarah, dan sepenuhnya disesuaikan dengan konteks dimana mereka melakukan PPL. Namun, jenis dan luaran kegiatan yang dihasilkan belum dapat terukur. Selain belum dapat terukur, aktivitas yang mereka lakukan ternyata belum dianggap relevan dengan bidang keilmuan AP dan belum menyediakan pengalaman pembelajaran yang maksimal bagi mahasiswa yang melakukan PPL.

Kurikulum Administrasi Pendidikan FIP UNM selalu ditinjau kembali setiap 4 tahun. Kurikulum yang dikembangkan adalah berdasarkan kesepakatan bersama prodi yang tergabung dalam Asosiasi Prodi Administrasi dan Manajemen Pendidikan Indonesia dan diskusi yang difailitasi oleh organisasi profesi Ikatan Sarjana Manajemen dan Administrasi Pendidikan Indonesia.

Berdasarkan Rencana Strategis

Administrasi Pendidikan FIP UNM tahun 2015 2019, kompetensi luaran yang ingin dihasilkan leh prodi AP untuk program sarjana adalah lulusan yang menguasai konsep teoretis dan mampu mengaplikasikan keashliannya di bidang manajemen, kepemimpinan pedidikan, perencanaan pendidikan, supervisi pendidikan, dan pengambilan keputusan dan kebijakan pendidikan (Administrasi Pendidikan, 2015). Jika melihat pernyataan luaran tersebut, terlihat bahwa alumni AP diharapkan bekerja tidak sebagai tenaga pendidik (guru), melainkan sebagai tenaga di bidang kependidikan. Tugas tenaga kependidikan berdasarkan UU Sisdiknas taun 20013 dan Permenristekdikti Nomor 44 tahun 2015 adalah untuk melaksanakan administasi, pengelolaan, pengembangan, pelayanan teknis, yag dapat menunjang proses penyelenggaraan pendidikan.

Kajian tentang Kurikulum AP ini menjadi langkah krusial untuk menentukan apa sebenarnya yang harus dilakukan oleh mahasiswa AP ketika mereka memprogramkan mata kuliah PPL. Hasil penelitian memperlihatkan bahwa mahasiswa tidak memiliki program dan kegiatan yang jelas, bahwa ada kesan maka kuliah PPL hanya sekedar menghabiskan waktu di unit tempat pelaksanaan PPL. Praktik pengalaman lapangan yang dialami oleh mahasiswa sifatnya lebih insidential, bahkan menurut mahasiswa tidak relevan dengan apa yang selama ini mereka pelajari di kampus.

Komponan PPL ini termasuk yang paling jarang dibicarakan. Luasnya kompetensi yang harus dicapai, seharusnya menjadi tantangan bagi prodi AP untuk menyesuaikan PPL yang dilakukan mahasiswa dengan kompetensi yg ingin dicapai. Panduan PPL yang disediakan oleh Lembaga Pengabdian Masyarakat (LPM) UNM hanya menyedian panduan untuk mahasiswa calon guru. Di mana, PPL merupakan bagian dari kurikulum pendidikan guru yang memberi tempat bagi calon guru untuk lebih mengenali tentang profesinya.

Menurut Direktur Pembelajaran (2016), tujuan PPL secara umum adalah menyediakan pengalaman nyata dan kontekstual bagi mahasiswa sesuai dengan bidang yang menjadi keahliannya kelak. Hasil penelitian memperlihatkan bahwa 
pengalaman nyata dan kontekstual ini yang belum tersedia dalam program PPL prodi AP. Studi dokumentasi mengenai komponen penilaian PPL juga memperlihatkan bahwa aspek penilaian lebih fokus pada aspek kedisiplinan, $\mathrm{d}$ bukan pada aspek kompetensi yang harus dimiliki oleh mahasiswa AP (UPT PPL UNM, 2016). Komponen penilaian ini berbeda dengan PPL yang dilaksanakan untuk pendidikan guru. Dimana penilaian yang diberikan tidak hanya fokus pada kedisiplinan, tetapi juga pada aspek keterampilan mengajar. Nilai PPL mahasiswa ditentukan berdasarkan aspek kedisiplinan, kelancaran dalam melaksanakan tugas, kerjasama, hubungan yang harmonis, dan kualitas dan kuantitas hasil program (Administrasi Pendidikan, 2016).

\section{Pola Pelaksanaan PPL AP}

Pola pelaksanaan PPL secara umum memerlukan perhatian dan kajian lebih dalam jika dikaitkan dengan Kurikulum Pendidikan Tinggi di UNM. Tantangn ini menjadi semakin berat karena fokus UNM adalah di dua bidang, yaitu bidang pendidikan dan non-kependidikan. Hasil penelitian memperlihatkan bahwa pelaksanaan PPL di prodi AP, untuk prodi non-kependidikan belum terlaksana secara maksimal. Pola pelaksanaan PPL baru pada tahap mengorganisir penempatan mahasiswa di lokasi tempat pelaksanaan PPL, penentuan jadwal PPL, dan penunjukan dosen pendamping. Proses dan isi pelaksanaan PPL itu sendiri belum memiliki panduan yang jelas.

Hasil penelitian ini memperlihatkan bahwa tantangan untuk pengembangan program PPL prodi AP cukup besar. Hal ini disebabkan karena unit/lokasi pelaksanaan PPL bagi mahasiswa prodi AP cukup bervariasi, bukan hanya sekolah tetapi juga kantor dinas pendidikan, UPTD, dan lembaga lain yang terkait dengan kompetensi luaran yang akan dicapai. Fokus, tujuan, dan sasaran program PPL untuk masing-masing unit tentu berbeda karena harus disesuaikan dengan tupoksi masingmasing unit. Bagaimana kesesuaian antara unitunit tersebut dengan kompetensi yang akan dicapai memerlukan kajian agar program PPL ini bisa memberikan pengalaman pembelajran yang bermakna kepada mahasiswa peserta PPL.

Salah satu isu utama yang dikemukakan oleh mahasiswa adalah bagaimana mereka mengaplikasikan atau belajar tentang hal-hal praktis berdasarkan teori yang sudah mereka pelajari di kampus. Dokumen jurnal PPL Prodi AP memperlihatkan bahwa mahasiswa sebenarnya dituntut untuk membuat jurnal harian mengenai aktivitas yang mereka lakukan selama mengikuti program PPL. Jurnal harian ini berisi tanggal, aktivitas, dan luaran yang dihasilkan (Jurnal PPL AP, 2016). Namun, karena tidak adanya tujuan, sasaran, dan target yang jelas mengenai aktivitas yang seharusnya yang mereka lakukan, jurnal ini akhirnya tidak terisi secara optimal.

\section{Kerjasama dan Koordinasi dengan Stakeholder} Terkait

Salah satu tantangan dalam pelaksanaan PPL untuk program kependidikan adalah kurang jelasnya peran dan tanggung jawab masing-masing mitra, dalam hal ini Universitas dan Sekolah (Allen \& Wright, 2014). Menurut mereka, hal ini menimbulkan dampak dimana mahasiswa yang sedang melakukan PPL harus mendefinisikan sendiri tujuan mereka mengikuti PPL. Lebih lanjut, mereka menjelaskan bahwa isu sinergitas bagi sesama mitra dalam pelaksanaan PPL membuat mahasiswa PPL harus memperjelas sendiri tentang tujuan dari praktikum yang mereka lakukan. 
Minimnya kerjasama dan koordinasi dengan stakeholder terkait, juga terjadi pada pelaksanaan PPL program studi AP.

Hasil penelitian memperlihatkan bahwa sebagian besar unit tempat pelaksanaan PPL bertanya tentang prodi Administrasi Pendidikan. Menurut mahasiswa, mereka harus menjelaskan kepada unit tempat mereka melaksanakan PPL tentang bidang Administrasi Pendidikan, baik dari segi keilmuan maupun hal-hal praktis yang bisa mereka kerjakan. Hal ini memperlihatkan bahwa sebelumnya, tidak terjalin komunikasi yang baik antara prodi dan unit dimana mahasiswa akan ditempatkan dalam program PPL mereka. Kondisi ini, bisa menimbulkan ketidaknyamanan bagi mahasiswa PPL, bahkan berdampak terhadap jenis-jenis tugas yang diberikan oleh pamong kepada mereka. Allen dan Wright (2014) bahkan menyebutkan hal ini bisa menimbulkan rasa frustrasi bagi mahasiswa PPL. Di lapangan, beberapa pekerjaan terkesan sangat teknis, bahkan ada yang menurut mereka tidak relevan dengan kajian bidang keilmuan mereka di Administrasi Pendidikan. Mahassiwa merasa tidak menemukan hal baru yang menantang yang membuat mereka belajar salaam mengikuti PPL.

Kerjasama dan koordinasi ini perlu dilakukan, baik antara mitra internal (prodi AP dan UPT PPL UNM), maupun antara UNM dengan mitra eksternalnya. Hal ini penting untuk dilakukan karena prodi AP berbeda dengan prodi pendidikan guru yang selama ini menjadi fokus pelaksanaan PPL di UNM. Kerjasama dan koordinasi ini diharapkan bisa menghasilkan panduan PPL, baik untuk PPL reguler maupun KKN PPL terpadu. Panduan PPL diharapkan berisi tujuan, sasaran dan luaran yang jelas. Peran pamong dan dosen pembimbing juga perlu diperjelas dalam panduan PPL, agar terjadi sinergitas antara mahasiswa, pamong, dan dosen pembimbing. Selain itu, panduan perlu menegaskan peran masing-masing, baik UNM maupun stakeholder eksternal terkait seperti yang dijelaskan oleh Allen dan Wright (2014).

\section{SIMPULAN DAN REKOMENDASI}

Hasil penelitian memperlihatkan bahwa pelaksanaan PPL untuk Prodi AP belum terlaksana secara maksimal. Beberapa kendala yang ditemukan adalah belum jelasnya tujuan, sasaran dan luaran dari PPL, isu terkait peran pamong dan dosen pembimbing, dan minimnya koordinasi antara UNM dan stakeholder tempat pelaksanaan PPL.

Program dan kegiatan yang dilakukan oleh mahasiswa sangat bervariasi karena ditentukan oleh tempat dimana mereka melakukan PPL. Mahasiswa merasakan bahwa mereka tidak begitu merasakan manfaat dari PPL karena pekerjaan yang ditugaskan kepada mereka terkesan rutin, insidensial, dan terkadang tidak relevan dengan keilmuan yang mereka peroleh di kampus

Peran pamong dan dosen pembimbing dirasakan belum maksimal. Minimnya komunikasi dan koordinasi antara pamong, mahasiswa dan dosen pembimbing berdampak terhadap kualitas pelaksanaan PPL. Mahsiswa merasa kurang memperoleh bimbingan dan cenderung megalami kebingungan terutama pada saat awal pelaksanaan PPL.

Kerjasama dan koordinasi antara UNM dan unit dimana mahasiswa AP melaksanakan PPL 
masih sangat kurang. Koordinasi yang dilakukan hanya terkait penempatan, lokasi, jadwal pelaksanaan PPL, dan penentuan pamong dan dosen pendamping. Komunikasi dan koordinasi mengenai esensi PPL dan program kerja selama PPL masih belum terlaksana dan terkelola dengan baik .

\section{DAFTAR PUSTAKA}

Achmad Hasmi Hashona. 2014. Kajian Pelaksanaan Praktik Pengalaman Lapangan (PPL) Mahasiswa Fakultas Ilmu Tarbiyah Dan Keguruan Iain Walisongo Semarang, Cendekia, 12 (2), 333-351.

Administrasi Pendidikan UNM (2015). Profil Progam Studi Administrasi Pendidikan. Makassar: Universitas Negeri Makassar.

Administrasi Pendidikan UNM (2016). Laporan Kerja Praktik PPL Administrasi UNM. Makassar: Universitas Negeri Makassar.

Allen, J. M. \& Wright, S. E. (2014) Integrating theory and practice in the pre-service teacher education practicum, Teachers and Teaching: theory and practice, 20:2, 136151 ,

DOI: 10.1080/13540602.2013.848568

Barbour, R. S., \& Schostak, J. (2005). Interviewing and focus groups. In B. Somekh \& C. Lewin (Eds.), Research methods in the social sciences (pp. 41-48). London: Sage Publications Ltd.

Bayu Rizky Pratama, Niswah Lutfiyani, Irtifah Nugrahaini. 2010. Pengaruh Prestasi Praktik Pengalaman Lapangan (PPL), Penguasaan Kompetensi Profesional, Dan Motivasi Mahasiswa Terhadap Kesiapan Menjadi Guru Mata Pelajaran Ekonomi/Akuntansi Yang Profesional (Studi Kasus Mahasiswa Program Studi Pendidikan Akuntansi, 32(1), 11-17.

Bernard, Arismunandar, Faridah. (2016). Studi Tentang Pola Pelaksanaan Praktik Pengalaman Lapangan (PPL) Pendidikan Keguruan Universitas Negeri Makassar. Makassar: Universitas Negeri Makassar

Dasmo \& Sumaryati. (2014). Peran Guru Pamong dan Dosen Pembimbing terhadap Keberhasilan Program Pengalaman Lapangan (PPL) Mahasiswa. Jurnal Formatif, 4 (1), 56-64.

DeAngelis, K.D., \& O'Connor, N.K. (2012). Examining the Pipeline into Educational Administration: An Analysis of
Applications and Job Offers. Educational Administration Quartery 48(3), 468-505.

Direktorat Pembelajaran. (2016). Panduan Pendidikan Profesi Guru. Jakarta: Direktorat Jenderal Pembelajaran dan Kemahasiswaan, Kementerian Riset, Teknologi, dan Pendidikan Tinggi.

Direktorat Pendidikan Tinggi. (2013). Panduan Pengembangan Kurikulum LPTK. Jakarta: Direktorat Pendidikan Tinggi, Kementerian Pendidikan dan Kebudayaan.

Fitzgerald, T. (2007). Documents and documentary analysis: Reading between the lines. In A. Briggs \& M. Coleman (Eds.), Research methods in educational leadership and management (2nd ed.). Los Angeles: Sage Publications.

Hamalik, Oemar. (2009). Pendidikan Guru Berdasarkan Pendekatan Kompetensi. Jakarta: Bumi Aksara.

Ni'mah, Fahmi, U. (2014). Pengaruh Minat Profesi Guru, Locus of Control Internal, Peran Guru Pamong dan Prestasi Belajar terhadap Kesiapan Mahasiswa Menjadi Guru pada Jurusan Pendidikan Ekonomi Fakultas Ekonomi Universitas Negeri Semarang. Economic Education Analysis Journal, 3 (2), 336-342.

Perakyla, A. (2008). Analyzing talk and text. In N. K. Denzin \& Y. S. Lincoln (Eds.), Collecting and Interpreting Qualitative Materials. (pp. 351-374). Thousand Oaks, CA: SAGE Publications, Inc.

Peraturan Menteri Riset, Teknologi, dan Pendidikan Tinggi. (2015). Standar Nasional Pendidikan Tinggi. Jakarta.

Peraturan Presiden. (2012). Peraturan Presiden Nomor 8 Tahun 2012 tentang Kerangka Kualifikasi Nasional Indonesia. Jakarta: Pemerintah Republik Indonesia

Presiden Republik Indonesia. (2003). UndangUndang Republik Indonesia Nomor 20 tahun 2003 tentang Sistem Pendidikan Nasional. Jakarta. 
Program Studi Administrasi Pendidikan. (2015). Rencana Strategik Jurusan AP tahun 2015 - 2019. Makassar: Prodi AP FIP UNM.
UPT PPL UNM (2016). Panduan Pelaksanaan Program Pengalaman Lapangan. Makassar: Universitas Negeri Makassar 